\title{
Cord blood hemoglobin levels in relation to maternal anemia
}

\author{
Agrawal R. ${ }^{1}$, Srivastava P. ${ }^{2}$ \\ ${ }^{1}$ Dr. Rohit Agrawal, Assistant Professor, Department of Pediatrics, T.S. Misra Medical College and Hospital, Lucknow, \\ ${ }^{2}$ Dr. Prachi Srivastava, Assistant Professor, Department of Obstetrics and Gynecology, T. S. Misra Medical College and \\ Hospital, Lucknow.
}

Corresponding Author: Dr. Prachi Srivastava, Assistant Professor, Department of Obstetrics and Gynecology, T.S. Misra Medical College and Hospital, Lucknow. Email id: dr.prachi26@gmail.com

\begin{abstract}
Introduction: Maternal anemia is a significant problem. Mothers with anemia are likely to deliver anemic babies. Cord blood hemoglobin can be used to diagnose neonatal anemia. Materials and methods: This was a cross sectional study conducted from January 2017 to January 2018 in Department of Pediatrics and Department of Obstetrics and Gynecology at T.S. Misra Medical College and Hospital. 100 mothers delivering in labor room and their newborns were included in the study. Maternal hemoglobin was estimated prior to delivery. After the delivery of baby cord blood hemoglobin was collected. Cord blood hemoglobin of anemic and non-anemic mothers were compared. Anemic mothers were categorized as mild, moderate and severe. We compared cord blood hemoglobin of babies in all three groups and also with cord blood hemoglobin of non-anemic mothers. Results: Difference between mean cord blood hemoglobin of anemic and non-anemic mothers was found to be statistically significant. Difference between cord blood hemoglobin of all three groups (mild, moderate and severe anemia) found to be statistically significant. Conclusion: This study shows direct correlation between maternal and fetal hemoglobin levels. We stress the importance of preventing maternal anemia and maintaining adequate iron storage in mothers during pregnancy to ensure better maternal and fetal outcome. We also emphasize the importance of cord blood hemoglobin for early diagnosis of neonatal anemia.
\end{abstract}

Key words: Anemia, Maternal hemoglobin, Cord blood hemoglobin

\section{Introduction}

Anemia is a very common medical disorder during pregnancy affecting nearly $50 \%$ of pregnant women globally. This includes nearly $75 \%$ of women in developing countries[1,2].

WHO defines maternal anemia as hemoglobin level less than $11 \mathrm{gm} / \mathrm{dl}$ during pregnancy. It is further classified as mild ( $\mathrm{Hb}$ levels: $10-10.9 \mathrm{gm} / \mathrm{dl})$, moderate $(\mathrm{Hb}: 7-$ $9.9 \mathrm{gm} / \mathrm{dl})$ and severe $(\mathrm{Hb}<7 \mathrm{gm} / \mathrm{dl})[1]$.Mothers with anemia are more likely to deliver anemic babies.

Umbilical cord hemoglobin is an important hematological parameter which though promising is very much underutilized [3]. It can be utilized for early diagnosis of anemia in new born babies. This study was conducted to find correlation between maternal anemia and cord blood hemoglobin levels to reinforce that umbilical cord hemoglobin levels can be implemented routinely to improve neonatal outcomes.

Manuscript received: $8^{\text {th }}$ July 2018

Reviewed: $18^{\text {th }}$ July 2018

Author Corrected: $26^{\text {th }}$ July 2018

Accepted for Publication: $31^{\text {st }}$ July 2018

\section{Materials and Methods}

This was a cross sectional study conducted in T.S. Mishra Medical College and hospital, Lucknow.

Type of study- cross sectional study

Duration of study-conducted for a period of one year from January 2017 to January 2018

Place of study- Department of Pediatrics and Department of Obstetrics and Gynecology combinedat T.S. Mishra Medical College and hospital, Lucknow.

Sampling method-100 women whodelivered in T.S. Mishra medical college and hospital and their newborn babies were included in the study.

Inclusion criteria- singleton full term neonates $(>37$ weeks) delivered vaginally or by cesarean section with no other maternal and fetal complications apart from maternal anemia. 
Exclusion criteria- Subjects with any kind of maternal or fetal complications in antenatal period apart from maternal anemia were excluded from the study.

Methodology- Maternal hemoglobin was estimated prior to delivery. After the delivery of baby cord blood hemoglobin was collected. Umbilical cord was clamped after delivery of infant and before expulsion of placenta. Cord blood was collected from umbilical vein from placental end of clamped and separated cord. Hemoglobin estimation was done from cord sample.
Based on maternal hemoglobin levels, mothers were classified into anemic $(\mathrm{Hb}<10 \mathrm{gm} / \mathrm{dl})$ and non anemic $(\mathrm{Hb}>10 \mathrm{gm} / \mathrm{dl})$ Cord blood hemoglobin of anemic and non anemic mothers were compared. As anemic mothers were categorized into mild, moderate and severe, we compared cord blood hemoglobin of babies in all three groups. Comparison was also made with cord blood hemoglobin of non anemic mothers.

Statistical analysis was done using SPSS21. Student $\mathrm{t}$ test was used to determine level of significance.

\section{Results}

Analysis of demographic profile showed the mean age of anemic mothers to be $26.72 \pm 1.34$ yrs and mean age of non anemic mothers to be $25.82 \pm 2.32$ years. Out of total 100 patients included in the study, 65 patients were from rural area while 35 patients were from urban area. The mean maternal hemoglobin in anemic mothers was found to be $8.67 \pm 0.5$ $\mathrm{gm} / \mathrm{dl}$ and in non anemic mothers was found to be $11.23 \pm 0.34 \mathrm{gm} / \mathrm{dl}$.

Out of 100 mothers enrolled for study based on inclusion and exclusion criteria, 47 patients (47\%) were anemic while 53 patients (53\%) were non anemic. Amongst anemic mothers, 23(48.9\%) were mildly anemic with hemoglobin level between 10-10.5 gm/dl, 19(40.4\%) were moderately anemic with hemoglobin level between 7-9.9gm/dl and 5(10.7\%) were severely anemic with hemoglobin level less than $7 \mathrm{gm} / \mathrm{dl}$. Amongst 100 babies delivered, 90 babies were full term babies and 10 babies were preterm babies.

Mean cord blood hemoglobin between anemic and non anemic mothers was compared and the difference was found to be statistically significant (Table-1).

Cord blood hemoglobin of all three groups (patients with mild, moderate and severe anemia) was compared and difference was found to be statistically significant (Table 2).

Table-1: Comparison of cord blood levels between anemic and non anemic mothers.

\begin{tabular}{|c|c|c|c|}
\hline Group & Mean age (in years) & $\begin{array}{c}\text { Mean maternal } \\
\text { hemoglobin (in gm/dl) }\end{array}$ & $\begin{array}{c}\text { Meancord blood } \\
\text { hemoglobin (in gm/dl) }\end{array}$ \\
\hline Anemic mothers & $26.72 \pm 1.34$ & $8.67 \pm 0.5$ & $14.06 \pm 1.2$ \\
\hline Non anemic mothers & $25.82 \pm 2.32$ & $11.23 \pm 0.34$ & $16.22 \pm 0.45$ \\
\hline
\end{tabular}

$\mathrm{P}$ value $<0.05$

Table-2: Comparison of mean maternal hemoglobin levels with cord blood hemoglobin

\begin{tabular}{|c|c|c|c|c|}
\hline $\begin{array}{c}\text { Severity of maternal } \\
\text { anemia }\end{array}$ & $\begin{array}{c}\text { Mean hemoglobin } \\
\text { (gm/dl) }\end{array}$ & No. of patients & $\begin{array}{c}\text { Mean cord blood } \\
\text { hemoglobin (gm/dl) }\end{array}$ & P value \\
\hline $\begin{array}{c}\text { Mild (Hb: } 10-10.9 \\
\text { gm/dl) }\end{array}$ & $10.3 \pm 0.13$ & 23 & $15 \pm 0.72$ & $\mathrm{P}<0.05$ \\
\hline $\begin{array}{c}\text { Moderate (Hb: } 9.9-7 \\
\text { gm/dl) }\end{array}$ & $9.1 \pm 0.62$ & 19 & $14.6 \pm 0.88$ & $\mathrm{P}<0.05$ \\
\hline Severe $(<7 \mathrm{gm} / \mathrm{dl})$ & $6.5 \pm 0.42$ & 6 & $13.1 \pm 0.79$ & $\mathrm{P}<0.05$ \\
\hline
\end{tabular}

\section{Discussion}

Survival of neonates can be increased by improved maternal care in antenatal period and early diagnosis and treatment of neonatal problems. Neonatal anemia is one of the problems affecting neonates of anemic mothers. Early diagnosis and treatment of neonatal anemia can go a long way in improving neonatal 
outcome. Cord blood hemoglobin can be used for early diagnosis of neonatal anemia. This study was conducted to find correlation between cord blood hemoglobin and maternal hemoglobin and thus establishing the utility of cord blood hemoglobin in diagnosis of neonatal anemia.

This study was conducted on 100 patients and their newborn babies. It was found in study that there was direct correlation between maternal hemoglobin and cord blood hemoglobin levels. Thus, babies with mothers who had lower blood hemoglobin levels also showed lower values of cord blood and this reduction of fetal hemoglobin was significant when compared to non-anemic mothers. This observation was contrary to popular belief that fetus continues to extract iron even from anemic mother to fulfill its requirement.

Sweet et al [4] in her study showed that mothers with iron deficiency anemia during pregnancy gave birth to newborns with lower hemoglobin levels.Similar findings were seen in study by Sareen A etal [5]. In his study Debbarma et al [6] found a linear relationship between maternal hemoglobin, cord blood hemoglobin and birth weight of newborns.

Sisson TRC et al [7] and Nhonolietal [8] found that if mother was iron deficient and anemic, then the newborn too had lower hemoglobin levels and low iron in cord blood. Singla et al [9] also showed significant association between maternal hemoglobin levels and cord blood iron levels. Fenton et al [10] found direct correlation between maternal ferritin and cord blood ferritin levels.

However in his study done by Marmoury GH et al [11], no association was seen between maternal and cord blood hemoglobin levels. Najeeba CM et al [12] showed decrease in cord blood levels of hemoglobin with decreasing maternal hemoglobin levels. However, this reduction was not statistically significant.Cantwell et al [13] also showed that mothers who were not given adequate iron in pregnancy still had similar levels of cord blood hemoglobin.

Bhargava et al [14] reported that iron depletion in mother did not have any significant effect on the fetus.Rusia et al [15] found that maternal hemoglobin levels did not correlate with cord blood hemoglobin levels, however, found it to be correlated directly with cord blood ferritin levels. Teref B et al [16] in his study showed reduced iron stores in neonates born of mothers with anemia compared to non anemic mothers. He also showed reduced hemoglobin levels in newborns of anemic mothers compared to non anemicones. This finding correlates with our study too. In previous studies it has been suggested that fetus continues to extract iron from mother regardless of her iron status. However, many recent studies including our study shows thatiron supply to fetus is nonetheless affected in maternal anemia and fetus extract iron from mother in direct proportion to mother's level.

Iron transportation occurs actively from mother to fetus. There occurs upgradation of iron transport proteins in placenta in iron deficient states. However placental mechanisms of iron transport from mother to fetus may be affected in high degrees of maternal anemia, thus, causing lower levels of cord blood hemoglobin as also shown in our study.

Our study also had certain limitations. Sample size was small. Iron status of mother and baby was not determined. However, it is likely that such mothers and their babies had decreased iron stores.

\section{Conclusion}

This study thus, shows direct correlation between maternal and fetal hemoglobin levels. we, therefore stress the importance of preventing maternal anemia and maintaining adequate iron storage in mothers during pregnancy to ensure better maternal and fetal outcome. We also emphasize the importance of cord blood hemoglobin for early diagnosis of neonatal anemia and early intervention if required.

Funding: Nil, Conflict of interest: None initiated, Perission from IRB: Yes

\section{References}

1. WHO.Iron deficiency Anemia Assessment, Prevention and control. A Guide for Program Managers. Geneva, Switzerl and: WHO;2001

2. McLean E, Cogswell M, Egli I, et al. Worldwide prevalence of anaemia, WHO Vitamin and Mineral Nutrition Information System, 1993-2005.DOI:10. 1017 /S 1368980008002401

3. Elagri MM, Waggiallah HA. Assessment of hematological parametres of neonatal cord blood in anemic and non anemicmo thers. J Clin Exp Res 2013; $1(2): 22-25$

4. Sweet DG, Savage G,Tubman TRJ, Lappin TRJ. Study of maternal influences on fetal iron status at term using cord blood transferrin receptors. Arch Dis Child fetal Neonatal Ed 2001 Jan;84(1):40-43 


\section{Original Research Article}

5. Sareen A, Mahajan K, Singh S. Maternal anemia and its effect on cord blood hemoglobin. Indian Medical Gazette 2013 May;161-63

6. Debbarma R, Debbarma B, Devi A. Effect of maternal anemia on cord hemoglobin and birth weight of new borns. IOSR Journal of Dental and Medical Sciences 2015 July; 14(7):19-21

7. Sisson TR, Lund CJ. The influence of maternal iron deficiency on the newborn. DOI:10.1093/ajcn/6.4.376

8. Nhonoli AM, Kihama, FE, Ramji BD. The relation between maternal and cord serum iron levels and its effect on foetal growth in iron deficient mothers without malarial infection $\mathrm{Br} \mathrm{J}$ ObstetGynaecol 1975june;82 (6): 467-70

9. Singla PN, Chand S, Khanna S, Agarwal KN. Effect of maternal anaemia on the placenta and the newborn infant. Acta Paediatr Scand. 1978 Sep; 67 (5): 645-8.

10.Fenton V, Cavill I, Fisher J. Iron stores in pregnancy. Br J Haematol. 1977 Sep;37 (1):145-9.
11. Mamoury GH, Hamedy AB, Akhiaghi F. Cord Hemoglobin in Newborns in Correlation with Maternal Hemoglobin in Northeastern Iran. IJMS 2003Sep; 28 (3): 166-68.

12. Najeeba CM, Prabhu AS. Maternal Anaemia and its effect on Cord Blood Haemoglobin\& Newborn Birth Weight. IOSR 2015July;14(7):30-32.

13. Cantwell RJ. Iron deficiency anemia of infancy: some clinical principles illustrated by the response of Maoriinfants to neonatal parenteral iron administration. DOI:10.1177/000992287201100807

14. Bhargava M, Kumar R, Iyer PU, et al. Effect of maternal anaemia and iron depletion on foetal iron stores, birthweight and gestation. Acta Paediatr Scand. 1989 Mar;78(2):321-2.

15. Rusia U, Madan N, Agarwal N, et al. Effect of maternal iron deficiency anaemia on foetal outcome. Indian J Pathol Microbiol. 1995 Jul;38(3):273-9.

16. Terefe B, Birhanu A, Nigussie P, Tsegaye A. Effect of maternal iron deficiency anemia on the iron store of newborns in ethiopia. DOI:10.1155/2015/808204

\section{How to cite this article?}

Agrawal R, Srivastava P. Cord blood hemoglobin levels in relation to maternal anemia. Int J Pediatr Res.2018;5(7): 351354.doi:10.17511/ijpr.2018.i07.02. 